\title{
Cross-Cultural Comparison on Codes of Ethics for Interpreters ${ }^{*}$
}

\author{
FENG Man \\ Zhongnan University of Economics and Law, Wuhan; \\ Guangdong University of Economics and Law, Guangzhou, China
}

\begin{abstract}
The professional ethics has not been officially incorporated in either the education or the accreditation of professionals in China, with a code of ethics to be adapted and improved. Through comparison in both form and content between the Chinese code of ethics for interpreters and translators and those of the United States and Australia, similarities and differences are identified and analyzed. Based on a survey with professionals and quasi-professionals to investigate those differences, this paper tries to explore the underlying culture differences and their impacts on professional ethics in different countries. It is concluded that due to different cultural systems, people actually understand and implement in various ways the principle of impartiality, principle of accuracy, and provisions regarding working procedure, relationship with clients and colleagues, and interpreters' rights and working conditions. There also conveys different degree of humanism and legal consciousness in those documents. Taking insights of those differences, the paper also offers some suggestions for an internationalized and localized code of ethics for Chinese interpreters.
\end{abstract}

Keywords: interpreters and translators, professional ethics, cross-cultural comparison

\section{Introduction}

The professionalization of interpreters started in the early 1980s in China with the economic reform and opening-up policy. Its development has been driven by the rising boom of the overall translation industry (inclusive of interpreting business), of which the revenue has reached to 30 billion RMB according to a report posted at www.china.com.cn (2007). Interpreting business has become a growth area of the industry as quite a lot of international big events were respectively held in China like Beijing Olympic Games 2008, Shanghai World Expo 2010, etc.. However, the profession has encountered many challenges in its developing stage, particularly, an unstable working force of different level of qualifications, unethical behavior in the profession driven by profit and so on. It is vigorously advocated that professional ethics shall be incorporated into the education and the accreditation of professionals while the construction of code of ethics for Chinese interpreters is far from sufficient and satisfying. Under the aim towards an internationalized and localized code of ethics applicable to Chinese interpreters, a comparison study has been made between the existing Chinese code of ethics and those of Australia and the USA, hoping to find out the similarities and differences in the understanding and performing of professional conducts.

\footnotetext{
* Acknowledgements: This paper is supported by the "Fundamental Research Funds for the Central Universities" (No. 31541110201) and the "Teaching Research Funds of Zhongnan University of Economics and Law” (No. 2012YB15).

FENG Man, lecturer, School of Foreign Languages, Zhongnan University of Economics and Law; Ph.D. candidate, School of Translation and Interpreting Studies, Guangdong University of Economics and Law.
} 


\section{The Selected Codes of Ethics for Study}

In China, the regulation governing the interpreting service is normally covered by those set for the whole translation industry (it is also called the interpreting and translation industry in Western countries), listed as below: (1) Interim Provisions for China Aptitude Test for Translators and Interpreters, by General Office of the Ministry of Personnel, 2003; (2) Specification for Translation Service-Part 1: Translation, GB/T 19363.1 - 2003; replaced by the revised version: GB/T 19363.1—2008; (3) Target Text Quality Requirements for Translation Services, GB/T 19682 - 2005; (4) Code of Ethics for Translation Service, by TAC (Translator's Association of China), 2005; (5) Specification for Translation Service-Part 2: Interpretation, GB/T 19363.2-2006; and (6) Interim Procedures for Accreditation of Senior and First-Grade Translators, by the Ministry of Human Resources and Social Security, 2011.

The domestic documentation mainly focuses on how to maintain the quality of translation service and tries to standardize the professional operations while contents relevant to professional ethics for interpreters account for just a small proportion, which can be only found in two documents: GB/T 19363.2-2006 and the Code of Ethics for Translation Service (2005); as the later is the major source, therefore, we take it as our subject for study.

As for the comparative subjects, we selected the following documents from both Australia and the USA, two countries where interpreting business has been well established. Those documents are either national or local, general or specific, representing main-stream opinions at different levels: (1) AUSIT (Australian Institute of Interpreters and Translators Inc.) Code of Ethics (1995); (2) Ethics of Interpreting and Translating: A guide to Obtaining NATTI Credentials (2010) (NATTI: The National Accreditation Authority for Translators and Interpreters); and (3) CHIA (California Healthcare Interpreters Association) Standards for Healthcare Interpreters (2002).

Professional ethics is founded upon evolving moral rules to tell good and bad behaviors within a profession throughout the professional history. As morals rules are established by people within a culture under diverse value systems, the understanding and performing of moral goodness can never be universal even though the professional activities seem quite alike. This point is further endorsed by the differences presented in the codes of ethics when studying them with an exploring eye. Reading through each provision, not to our surprise, we find that although we seem to agree with general principles like confidentiality, impartiality, accuracy, professionalism, etc., there are still many nuances in understanding and implementing those principles. It is based on those differences we try to uncover the underlying cultural reasons and their impacts on the actual practice in China.

\section{Research Method}

This comparison study is consisted of two parts. The initial study is focused on the comparison of the text itself highlighting differences in style, genre, more on general linguistic aspect. The second study starts with the comparison of detailed provisions by five MTI (Master of Translation and Interpreting) students to take out provisions that they deem as more or less discrepant with the China's reality. Afterwards, a group of quasi-professionals and professionals (10 MTI students and 10 professionals, 20 in total) are investigated on whether they agree with the existence of those discrepancies and certainly their reasons for such an opinion. The investigation is carried out mainly through classroom discussion for MTI students and informal interviews with professionals. 
The major discrepancies contained in the subject documents are preliminarily grouped into four categories: (1) understandable, but hard to implement in reality; (2) difficult to understand; (3) understandable, but normally will not be put into a Chinese code of ethics; and (4) highly recommendable, but is missing in the Chinese code.

\section{Initial Comparison of General Aspects}

The initial comparison of general aspects is presented in Table 1.

Table 1

Comparison of General Aspect

\begin{tabular}{|c|c|c|c|c|c|}
\hline$\overline{\text { Document name }}$ & $\begin{array}{l}\text { Abbreviation for } \\
\text { document }\end{array}$ & Page & Contents & Annex & General language features \\
\hline $\begin{array}{l}\text { AUSIT code of ethics } \\
\text { (1995) }\end{array}$ & AUSIT & 8 & $\begin{array}{l}\text { Principles + detailed } \\
\text { stipulation }\end{array}$ & None & $\begin{array}{l}\text { Concise and plain English, frequent } \\
\text { use of negation words }\end{array}$ \\
\hline $\begin{array}{l}\text { Ethics of interpreting and } \\
\text { translation (a guide to } \\
\text { obtaining NATTI } \\
\text { credentials) (2010) }\end{array}$ & NATTI & 10 & $\begin{array}{l}\text { Principles + detailed } \\
\text { stipulation + concrete } \\
\text { examples }\end{array}$ & None & $\begin{array}{l}\text { Concise and plain English, use of the } \\
\text { second person pronoun, explanation } \\
\text { with concrete examples }\end{array}$ \\
\hline $\begin{array}{l}\text { CHIA standards for } \\
\text { healthcare interpreters } \\
\text { (2002) }\end{array}$ & CHIA & 86 & $\begin{array}{l}\text { Targeted document } \\
\text { with very detailed } \\
\text { information }\end{array}$ & Yes & $\begin{array}{l}\text { Approachable, specific language, } \\
\text { conforming to academic norms when } \\
\text { quoting. Frequent use of negation } \\
\text { words }\end{array}$ \\
\hline $\begin{array}{l}\text { Code of ethics for } \\
\text { translation service (2005) }\end{array}$ & TAC & 2 & $\begin{array}{l}\text { More principles than } \\
\text { concrete rules }\end{array}$ & None & $\begin{array}{l}\text { Formal language, only one negation } \\
\text { word is used. }\end{array}$ \\
\hline
\end{tabular}

In terms of pages, CHIA totals 86 ages, which tops the number. AUSIT code of eight pages is supplemented by NATTI document of 10 pages. Whereas, TAC is of the least volume, i.e., two pages. Disregarding that Chinese is a condense language carrying relatively more information; the fact does disclose some truth of Chinese people's dislike of rules and regulations.

The belief in good human nature that all man is born good and pure makes people emphasize on moral education, and firmly believe that moral teaching and persuasion can guide them to highest good, therefore a tradition to prioritize rules and regulations has found little appropriate soil to grow in China. (ZHANG \& YANG, 2012, p. 78)

Chinese traditional view towards etiquette and law placed the law as subordinate to the etiquette system which is the foundation of ancient China's society. Under such concept, the construction of laws was ignored for long and the legal consciousness was not well integrated into people's mind. Nevertheless, "the original sin is deeply rooted in Western society, the belief of evil nature of human being turns it natural to compile detailed rules and regulations with clear punishment measures to prevent evilness from happening” (YAO, 2010, p. 179). The tradition of valuing rule by law can also date back to the dominating "logos", a concept of the Greek philosophy which has been uniting people in pursuit of universal rules and codes. The function of rules is clear that they provide guidance and reference for people's professional conduct; therefore, China shall pay more attention to its rule construction. At the same time, punishing measures shall also be considered, because they can exercise the power of awe to hurdle the evil by demonstrating the consequences of violation in black and white.

Regarding the contents, TAC is of more general nature mainly depicting principles while the other three documents are loaded with more detailed information, of which the CHIA contains 86 pages of detailed 
provisions. This can be explained by the difference of high context and low context culture proposed by archaeologist Edward Hall (1976). Chinese culture is a high-context culture where message is encoded and decoded together with contextual clues, thus presumption has been made that background knowledge in relation with what has been written in the code should be known to readers. In contrast, Australia and the USA are two countries of relatively low context culture where people try to use explicit and overt language to convey information, and try to clarify boundaries through the use of language (Samovar \& Porter, 2000). For the sake of clearness, the annex of CHIA even offers examples to help readers understand what ethical conducts are and how to make ethical dilemmas under different situations. These two cultures demonstrate both strength and weakness in terms of rule-making. Normally, a high context culture tends to draft rules that can generalize different situations with explanation adaptable and flexible to changes, while at the mean time its ambiguity and vagueness may dilute the authority and binding power of rules. Rules of a low context culture tend to be very detailed, easy for people to follow but may be heavy and overloaded, inadaptable to the ever-changing realities and may leave loopholes for some unethical behavior. If we can combine the strengths of rule-making of both cultures, i.e., making general statement about principles accompanied with detailed explanation as well as feasible working flow, the shortcoming of vagueness and inadaptability could possibly be overcome. On one hand, it is easier for people to grasp the essence of the regulation; on the other hand, there will always be concrete information to refer to.

Viewing on language features, TAC is more formal than the other three. The formal language style is much owing to the Chinese culture of large power distance. Power distance is one of the five culture dimensions proposed by Geert Hofestede (1997) who based on a large-scale survey ranked the China's power distance index as 80, Australia's as 36 and the USA as 40 (2010). Even legal documents share common features in formality in all countries, however, various degree of formality can be easily noticed in normative documents like code of ethics. Differences in language style are significant in this kind of quasi-legal documents which set up rules and provide moral guidance for professional conduct. The Western convention adopts a more plain and approachable feature, attempting to shorten the distance between the leading institutions and individual practitioners. For example, the second personal pronoun "you" has been used in NATTI document, with an interactive approach rather than an autocratic stance. Much background information for drafting the code has been mentioned in CHIA and the absence of strong modal verbs like "shall" or "should" has placed the readers in a more equal status. Professional ethics requires self-discipline and a willingness to commit oneself, a more reader-friendly code serves teaching and persuading function better, as a consequence, the acceptability of the code can be improved. At present, there does exist a code of ethics for translation service in China, however, the effectiveness and efficiency shall be constantly reviewed, a linguistic approach to improve its function can be deemed as a new perspective, such as adopting a more reader-friendly policy for composing norms, a more specific language for operational procedures, and even an inspirational style for supplementary materials.

Another remarkable difference is that negation words have been frequently used in Western codes such as "shall not" and "decline”, etc., while only one negation word was found in TAC document. It serves as another proof for the culture difference in human nature belief. Chinese people, influenced by their belief in good human nature, are accustomed to raise positive moral standards and set up moral idols for people to follow. They are convinced that these ideal goals can be achieved through self-improvement and self-discipline. 
Whereas, the Western innate evilness in human nature thrusts lawmakers to strict laws and regulations, in which prohibited behaviors are well stated. This outlook on a negative side, according to ZHANG (2007), is due to the "scientific rationality" that is deeply planted in the Western academic mindset, featured with a perception at both macro and micro level, a focus not only on verification but also on falsification. As for them, one important path to the truth is to find out the false. The scientific rationality allows people to define morality from negative side and break it down into micro-level operational procedures. In current China, under the market economic system, the traditional morality has been undermined by the profit-centered concept with new values still under construction, it is not enough to only teach virtue and set moral models for people. A more comprehensive approach shall be applied to include those inhibited behavior to shape professional ethics from both the positive and negative side.

\section{Investigation Over the Differences in Detailed Provisions}

Reading through each provision, it becomes clear that even we share common in principles like principle of integrity, confidentiality, accuracy, impartiality and so on, we do have differences in understanding and implementing those principles. As mentioned above, five MTI students are requested to take out those provisions that may fit into the following four categories according to their judgment. The aim is to identify concrete differences conveyed between lines. Based on a parliamentary voting procedure, provisions gaining more than half votes are used as the base for the investigation. In the following, a group of 20 quasi-professionals (MTI students) and professionals are invited to comment on whether they agree with the existence of the following discrepancies supported with a reason. Because of the limit on length of the paper, only those provisions that are causing attention (half agreed) has been listed in Table 2 .

\section{Table 2}

Comparison of Differences in Detailed Provisions

\begin{tabular}{|c|c|}
\hline Category & Discrepant provisions (the source is put into parentheses) \\
\hline & $\begin{array}{l}\text { 1. Avoiding side conversations with either party. (CHIA) } \\
\text { 2. Interpreters shall convey the whole message, including derogatory or vulgar remarks, as well as } \\
\text { non-verbal clues. (CHIA) } \\
\text { 3. Decline to mix promotional activity for clients with interpreting or translation work. (AUSIT) } \\
\text { 4. Indicate clearly when interpreters are speaking on their own behalf... (CHIA) } \\
\text { 5. Document the provision of interpreting services, as required by each organization's policies. } \\
\text { (AUSIT) } \\
\text { 6. Interpreters and translators ought to be given the opportunity to comment on any alterations made to } \\
\text { their work a result of a second opinion and/or review by other interpreters or translators. (AUSIT) } \\
\text { 7. CHIA recommends that two interpreters work as a team for interactions lasting more than } 45 \\
\text { minutes, and, that interpreters be given a } 10-15 \text { minute break after working continuously for an hour. } \\
\text { 8. CHIA also recommends that organizations employing interpreters help protect the health and } \\
\text { well-being of their staff by offering workshops. (CHIA) } \\
\text { 9. Decline to undertake work beyond their competence or accreditation levels. (AUSIT) } \\
\text { 10. Shall not sub-contract work to interpreting and translating colleagues without permission from their } \\
\text { client. (AUSIT) } \\
\text { 11. When employed by an interpreting and translation agency for specific tasks, interpreters and } \\
\text { translators may present business cards representing that agency only-do not use personal cards or... } \\
\text { (AUSIT) } \\
\text { 12. Shall not solicit or accept gratuities or other benefits. (AUSIT, similar requirements in CHIA too) } \\
\text { 13. Shall not accept for personal gain any fees, favors, commissions or the like... in connection with } \\
\text { recommending to a client any person, business agency, substance, material matters, process or service. } \\
\text { (AUSIT) }\end{array}$ \\
\hline
\end{tabular}


(Table 2 continued)

\begin{tabular}{|c|c|}
\hline Category & Discrepant provisions (the source is put into parentheses) \\
\hline & $\begin{array}{l}\text { 1. If patent untruths are uttered or written, interpreters and translators shall convey these accurately as } \\
\text { presented. (CHIA) } \\
\text { 2. Patient Advocate role must remain an optional role for each individual healthcare interpreter in light } \\
\text { of the high skill level skill required and the potential risk to both patient and interpreter. (CHIA) } \\
\text { 3. If objectivity is threatened, interpreters and translators shall withdraw from the assignment. (AUSIT) } \\
\text { 4. If approached directly by a client, known to be a client of another interpreting or translation } \\
\text { professional or agency, do not accept any assignments offered without first conferring with, and } \\
\text { obtaining endorsement from, the other professional or agency. (CHIA) } \\
\text { 5. If approached independently by separate parties to the same legal dispute, an interpreter or translator } \\
\text { shall notify all parties and give the first party opportunity to claim exclusive right to the requested } \\
\text { interpreting or translation service. (CHIA) } \\
\text { 6. Disclose personal ties between the patient and the interpreter to the healthcare professional. Consider } \\
\text { withdrawing and requesting substitution by another interpreter when personal ties cause discomfort or } \\
\text { embarrassment, leading patients to avoid speaking freely. (CHIA) }\end{array}$ \\
\hline $\begin{array}{l}\text { c. Und } \\
\text { normal } \\
\text { into a } \\
\text { ethics }\end{array}$ & $\begin{array}{l}\text { 1. Even when ad-hoc interpreters may be ready to step in... These consequences increase healthcare } \\
\text { costs and liability, and lead to poor health outcomes. (CHIA) } \\
\text { 2. Facilitate the scheduling of follow-up appointments and to remind the patient or the receptionist to } \\
\text { request an interpreter. (CHIA) } \\
\text { 3. Title VI of the Civil Rights Act of } 1964 \text { establishes the need for professional healthcare interpreters } \\
\text { to ensure meaningful access to healthcare... (CHIA) } \\
\text { 4. After inquire about any questions or concerns the parties may have for each other, and to ensure that } \\
\text { the encounter has indeed ended. (CHIA) } \\
\text { 5. Examples. (CHIA, NAATTI) } \\
\text { 6. Interpreters and translators are not responsible for what clients say or write. (AUSIT) } \\
\text { 7. If recall and interpreting are being overtaxed, interpreters shall ask the speaker to pause, then signal } \\
\text { to continue. (AUSIT) }\end{array}$ \\
\hline $\begin{array}{l}\text { d. Highly } \\
\text { recommendable, but is } \\
\text { missing in the Chinese } \\
\text { code }\end{array}$ & $\begin{array}{l}\text { 1. Shall continue to develop their professional knowledge and skills. (AUSIT) } \\
\text { 2. Shall respect and support their fellow professionals. (AUSIT) } \\
\text { 3. Shall not exercise power or influence over their clients. (AUSIT) } \\
\text { 4. Shall frankly disclose any possible conflict of interest. (AUSIT) } \\
\text { 5. Shall explain their role to those unaccustomed to working with them. (AUSIT) } \\
\text { 6. Protect the interpreter's own privacy and safety. (CHIA) } \\
\text { 7. Refer to arbitration by the National Council of any dispute with other members and to accept the } \\
\text { Council decision as binding. (AUSIT) }\end{array}$ \\
\hline
\end{tabular}

From Table 2, we can see that subtle differences are contained in the three foreign codes. Most discrepancies rise from the CHIA document, which explains that even we agree on big issues like principles but we may understand them differently as shown in the survey. The more detailed the provisions are, the more nuances are disclosed. It is on those differences that we start to explore the underlying cultural factors.

\section{Principle of Impartiality}

The above items (a1-4; b1,3; d3,4,7) concern with the principle of impartiality. The neutral position and impartiality have always been emphasized in Western world in line with their pursuit of truth and their tradition of scientific reason. The linear thinking mode requires no grey area between black and white so as to avoid any interference with their judgment of the truth. The relatively individualistic culture provides a context that each individual takes responsibility for their own deeds without easily being influenced by others as long as not prohibited by the law; therefore, it is relatively easy to maintain impartiality comparing to a more collectivist culture. In China, a highly collectivist culture where human relations count in every aspect of social life, people are more likely to work with trust that is obtained through constant interaction and association. Therefore, it is not uncommon for Chinese interpreters to have side conversations with the communicative participants (against a1) or rather the reverse way; what is more, it is hard for them to convey embarrassing message at some social 
occasions as they often mediate in the conflicting situation and their education and cultural background allows them little space to convey information that greatly hurt the others' feelings (against a2). Provision a3 requires interpreters to decline to mix promotional activity for clients with interpreting or translation work, however, if the interpreter is employed directly by the client, they are bound to be loyal to and work for the best interest of the principal according to the Chinese traditional culture, interpreters are more likely to take on the side of their own client. For example, in the negotiation of a joint venture, the Chinese party is saying things in such a modest way that may be misunderstood by the foreign party, under this situation, the interpreter may do the promotion work to gain a more favorable image that he thinks the Chinese factory deserves.

\section{Principle of Accuracy}

Principle of accuracy has been dramatically explained, provisions deemed to have some distance with the reality are a2, 9; b1,3; and d1. These stipulations of accuracy are much related to the neutral role of interpreters, such as a2, b1, and b3, which has already been discussed. What shall be pointed out is that because China is still not an internationalized society, there are only a few equivalent bilinguals working in the profession, and many interpreters dispose inadequate knowledge of the culture of the working language, so it can be an extremely tough task to accurately convey both the verbal and non-verbal message. Its' noteworthy that four professionals argued that reasonable requirements shall be set for different interpreting task and for more demanding jobs, specific certificates shall be required.

Besides, a9 and $\mathrm{d} 1$ are the premises to ensure accuracy. Though taking interpreting tasks beyond one's competence as described in a9 is not unheard of in China, however most opinions supported the idea that this concept shall not be compromised no matter how hard it is to stick to it. Also agreement is reached that more attention shall be paid to the professional development of interpreters although it has been ignored by the short-term-profit-oriented agencies that do not really care for the long-term welfare of the interpreter. The professional association, as the leader and promoter of the profession, shall undoubtedly take more responsibilities in these aspects.

\section{Interpreters' Working Procedure}

Detailed procedures are set for the interpreters in both AUSIT and CHIA while they are missing in TAC. Provisions a5, c2, 4, and 7 are pointed out to be understandable but not necessary to put into a code of ethics as it sounds obvious or simply not habitual. These points reflect the difference between high context culture and low context culture as discussed previously. In high context culture, experience plays an important role in social activities, people rely on more contextual information than what is written and spoken, that is why less written reports are required for routine work unless truly necessary. It is not common for people of a high context culture to put everything in written that is already conventionalized in the society thus c2, 4, and 7 are considered unnecessary parts of a code of ethics. In fact, the attention to micro-level details with an exploring mind is what we are not good at, describing the working procedures into details can help us avoid ambiguity and provide guidance for the newcomers. Why shall we not have a try and standardize the work flow into an annex?

\section{Relationship With Clients and Colleagues}

Provisions b4-6 and d3 tell about how to deal with clients and colleagues, among which three provisions are considered hard to understand. For example, in China, if it is the client that approaches an interpreter, it is interpreter's right to accept the client based on their own decision. However in b4, the interpreter shall first 
confer with, and obtain endorsement from the other professional or agency working with that client. This shows the consideration of respecting the others working with that client. In b5, if approached independently by separate parties to the same legal dispute, an interpreter or translator shall notify all parties and give the first party opportunity to claim exclusive right to the requested interpreting or translation service. This is the confinement set for the sake of a fair-play market order and of confidentiality. Provision b6 requests interpreter to "Disclose personal ties between the patient and the interpreter to the healthcare professional. Consider withdrawing and requesting substitution by another interpreter when personal ties cause discomfort or embarrassment, leading patients to avoid speaking freely". Things turn out to be a bit different: Chinese clients often seek for interpreter that they can trust or have a personal relationship with and even when they feel embarrassed to say something, it is them who ask interpreters to withdraw from the service, not the interpreters themselves. Chinese interpreters feel more comfortable to leave the choice to their clients. Therefore, we suggest that the client who receives the service, shall reserve the right to change interpreter no matter the service is charged or totally free.

There are also nuances in gifting as shown in a12 and a13. To maintain a neutral role, interpreters are required not to accept gifts and gratuities, and shall turn down any form of remuneration when recommending someone or something to their client. In a relation-based society as in China, gifting is quite common; any thanks to interpreter's service may be in the form of a gift. The declining to gifts can hurt feelings and faces of the gifter. A possible solution is that a reasonable limit shall be set for receiving gifts. On the other hand, subcontracting is also popular, if interpreters take a small portion of the service fee offered by the sub-contracted interpreter, it is often not considered as unethical as long as the subcontracting ends well. Certainly the good-will of sub-contracting the job can also be reciprocated in other ways.

Provision $\mathrm{d} 2$ and $\mathrm{d} 7$ define interpreter's relationship with colleagues. Pointing to the view that "two of a trade never agree”, interviewees suggest that a good relationship with colleagues is essential to maintain the image and reputation of the profession. If conflicts arouse among peers, a special organism within the industry shall offer ways of settlement for their disputes. To hurdle unethical behavior, a variety of punishing measures such as black list, public disclosure, canceling of professional certificates, etc., shall be carried out for unethical behavior that has or has not been regulated by the law.

\section{Interpreters' Rights and Working Conditions}

Provisions a6-8, c6-7, and d5-6 are targeted at the protection of interpreters' rights and working conditions, which are often missing in the Chinese stipulations. The reason is more related to the understanding of code of ethics. The explanation provided by Encyclopedia Baidu (2012) is:

Professional ethics refers to the ensemble of moral rules, norms and qualities closely related to and characterized by the professional activities, it is both the requirements for professionals to follow and obligations and duties that the profession holds for the society.

This definition obviously is centered on three keywords: requirements, obligations, and duties. However, if referring to the Wikipedia page, the aim to build up professional ethics is not only to be responsible for the client and society, but also to protect the professionals' interests and the dignity of the profession.

Most professions have internally enforced codes of practice that members of the profession must follow, to prevent exploitation of the client and preserve the integrity of the profession. This is not only for the benefit of the client but also the benefit of those belonging to the profession. (Wikipedia, 2010) 
In conformity with this aim, there are quite a lot of stipulations targeting at improving working conditions and protecting labor rights, for instance, d6 clearly states to protect the interpreter's own privacy and safety. Concerning c6, some interviewees are a bit confused why we should tell the obvious truth that "translator and interpreters are not responsible for what clients say or write”.

Actually, we understand that it may serve as a duty waiver for transmitting the hostile message in some countries who may be deemed as guilty, thus it eliminates the hesitation that interpreters shall transmit whatever mentioned by their clients. The big contrast here is that labor protection is taken into account in almost every level of documentation while in China the professional association, even acting as the leader of the profession still turns a blind eye towards this aspect due to the lack of legal mindset and China's incomplete labor protection mechanism. China's code shall take interpreter's intellectual property rights, working conditions, and labor protection into account, calling for the establishment of both norms and rights of the profession. Only being aware of this gap, shall we make efforts towards better working conditions, strive for more rights, and gain more respect for the profession.

\section{Humanism and Legal Consciousness Contained in the Codes}

The category c brings up an interesting topic why there be so many statements deemed as unnecessary in a Chinese code, for example, c2 and c4 stipulating the working conditions, c6 and c7 talking about interpreters' rights, c1 explaining why only professional interpreter shall be used in a medical arena, c3 indicating the legal source of the provision, and c5 giving examples for further explanation, all of which are rare to see in a Chinese code. The possible answer is the view towards a normative document. In China, it represents power and authority, which is for people to follow and obey, not to help explain, not even mention to clarify confusion. However, the human touch of a normative document can well serve its function if used wisely and appropriately.

Quoting the legal source for a specific provision reflects the legal consciousness. This consciousness may extend to the other cares. The b2 is pointed at the discrimination in medical service with a certain allowance "Patient advocate role must remain an optional role for each individual healthcare interpreter in light of the high skill level skill required and the potential risk to both patient and interpreter”. On one hand, the interpreter shall advocate non-discrimination during the work however it humanly admits that it could turn to be optional if interpreters feel risky to do so. Besides, the legal spirit can be found in stipulations concerning working conditions and labor rights protection, how to get along with clients and colleagues and so on. Although it allows interpreters to choose to act to a discriminatory behavior, it strongly requires that the interpreter shall not be bound with terms of confidentiality and impartiality when the violation of it is for the public order and interest. The dichotomy of those do's and don'ts also embodies the humanistic spirit.

\section{Conclusions}

Through the comparison study of codes of ethics of three countries, namely, China, Australia, and the USA, cultural differences contained in the codes are discovered and their impacts on professional ethics are also discussed. Based on the above study, we can have an insight into the construction of China's code of ethics by reflecting what can be borrowed and learned to adapt to both international practice and local culture. The build-up of professional ethics is a long-term and dynamic course, local laws and values shall be considered to enhance its construction and implementation, and so shall the humanity thoughts be promoted as well. 


\section{References}

Australian Institute of Interpreters and Translators Inc.. (1995). AUSIT code of ethics. Retrieved from http://ausit.org/files/codeofethics.pdf

Baidu. (2012). Professional ethics. Retrieved from http://baike.baidu.com/view/128231.htm

California Healthcare Interpreters Association. (2002). CHIA standards for healthcare interpreters. Retrieved from http://www.chiaonline.org/?page=CHIAStandards

Samovar, L. A., \& Porter, R. E. (2000). Communication between cultures. Beijing: Foreign Language Teaching and Research Press.

SU, X. D. (2008). Golden times for China's translation business with a revenue reaching to 30 billion RMB. Retrieved from http://www.china.com.cn/book/zhuanti/2008fy/2008-08/07/content_16155106.htm

The Hofstede Centre. (2012). National cultural dimensions. Retrieved from http://geert-hofstede.com/national-culture.html

The National Accreditation Authority for Translators and Interpreters. (2010). Ethics of interpreting and translating: A guide to obtaining NAATTI credentials. Retrieved from http://www.naati.com.au/PDF/Booklets/Ethics_Booklet.pdf

Translator's Association of China. (2005). Code of ethics for translation service. Retrieved from http://wenku.baidu.com/view/d5dfd48f680203d8ce2f243b.html

Wikipedia. (2010). Professional ethics. Retrieved from http://en.wikipedia.org/wiki/Professional_ethics

YAO, Y. M. (2010). Comparison of China and West ethical culture source. Chang Cheng, 12, 179-180.

ZHANG, H., \& YANG, C. (2012). Comparison of cultural impacts on professional ethics of Chinese teachers and Western teachers. Journal of Inner Mongolia Normal University (Educational Science), 25(6), 78-80.

ZHANG, S. Y. (2007). Greek spirit and science. Journal of Nanjing University (Philosophy, Humanities and Social Sciences), 2, 79-88. 